\title{
Fenofibrate monotherapy induced myositis and rhabdomyolysis
}

\author{
Balasubramaniam $B^{1}$, Selladurai $\mathbf{P}^{2}$, Sugathapala $\mathbf{A G H}^{\mathbf{3}}$ \\ ${ }^{1}$ Registrar, ${ }^{2}$ Senior Registrar, ${ }^{3}$ Senior Consultant Physician, Colombo South Teaching Hospital, \\ Kalubowila, Sri Lanka.
}
Corresponding Author: Balasubramaniam Branavan, Registrar in Medicine, Colombo South Teaching Hospital, Kalubowila, Sri Lanka, Email: hello.brana@live.com https://orcid.org/0000-0001-9160-3621

\begin{abstract}
Introduction
Rhabdomyolysis is a potentially life-threatening disorder due to release of toxic substances into the circulation following skeletal muscle damage by various factors including trauma, burn, infections, metabolic disorders including thyroid dysfunction, toxins and drugs. Fibrates are group of drugs used primarily for patient's with hypertriglyceridemia. Fenofibrate monotherapy induced rhabdomyolysis in a previously healthy patient is rare.
\end{abstract}

We report a previously healthy patient who has been on fenofibrate monotherapy developed rhabdomyolysis with secondary acute kidney injury.

\section{Case report}

A 52 year old gentleman found to have triglyceride of $280 \mathrm{mg} / \mathrm{dL}$, with $\mathrm{LDL}$ of $97 \mathrm{mg} / \mathrm{dL}$ and $\mathrm{HDL}$ of $43 \mathrm{mg} / \mathrm{dL}$ during routine medical checkup, started on fenofibrate $200 \mathrm{mg}$ daily, two weeks ago, presented with generalized muscle pain, lethargy, and passing dark color urine for 5 days duration. He denied any recent history of fever or sore throat suggestive of a viral illness. He did not have any episode of seizures, or strenuous activity and was not on any long-term medication. Physical examination did not reveal significant findings except muscle tenderness over bilateral thigh and calf regions.

Laboratory investigations showed creatinine kinase (CPK) of $43,077 \mathrm{U} / \mathrm{L}$, creatinine of $462.9 \mu \mathrm{mol} / \mathrm{L}$, sodium of $142.2 \mathrm{mmol} / \mathrm{L}$, potassium of $6.2 \mathrm{mmol} / \mathrm{L}$, AST of $2113 \mathrm{U} / \mathrm{L}$, ALT of $1302 \mathrm{U} / \mathrm{L}$, total bilirubin of $6.17 \mu \mathrm{mol} / \mathrm{L}$ and $\mathrm{LDH}$ of $7738 \mathrm{U} / \mathrm{L}$. Diagnosis of rhabdomyolysis with acute kidney injury was made and fenofibrate was immediately stopped. Medical management of hyperkalemia, fluid resuscitation and maintenance of fluids with isotonic saline, urine alkalization with sodium bicarbonate was provided to the patient. Urine output of more than $200 \mathrm{~mL} / \mathrm{hr}$ and urinary $\mathrm{pH}$ of more than 6.5 was maintained during hospital stay. Abdominal ultrasonography showed normal sized kidneys with evidence of acute renal parenchymal changes. Thyroid functions has been done showed TSH of $1.97 \mu \mathrm{IU} / \mathrm{mL}(0.27-4.2)$ and free $\mathrm{T}_{4}$ of $1.18 \mathrm{ng} / \mathrm{dL}$ (0.93-1.7) Three days after the presentation repeat investigations showed significant improvement including creatinine kinase (CPK) of $13,077 \mathrm{U} / \mathrm{L}$, creatinine of $262.9 \mu \mathrm{mol} / \mathrm{L}$, sodium of $142.2 \mathrm{mmol} / \mathrm{L}$, potassium of $4.2 \mathrm{mmol} / \mathrm{L}$, AST of $811 \mathrm{U} / \mathrm{L}$, and ALT of $512 \mathrm{U} / \mathrm{L}$. patient was discharged on the $7^{\text {th }}$ day with creatinine kinase (CPK) of 5,077U/L, creatinine of $192.9 \mu \mathrm{mol} / \mathrm{L}$, sodium of $143.1 \mathrm{mmol} / \mathrm{L}$, and potassium of $4.1 \mathrm{mmol} / \mathrm{L}$. Rapid improvement of clinical and biochemical profile after withdrawing drug with no other cause of myositis strongly suggestive of a fenofibrate induced rhabdomyolysis with acute kidney injury.

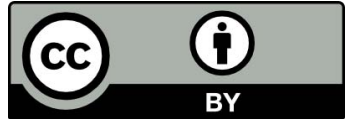

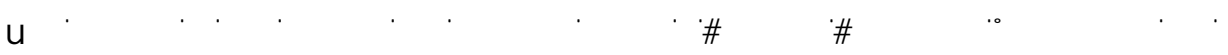

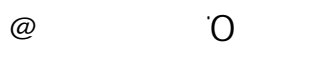




\section{Discussions}

Fibric acid derivative, fenofibrate, substantially reduces triglycerides while reduces low density lipoprotein (LDL) moderately andincreases high density lipoprotein (HDL). ${ }^{1}$ there are several serious side effects have been noted including myotoxicity with rhabdomyolysis, renal failure and hepatic toxicity. Rhabdomyolysis is characterized by damage of skeletal muscles following various causes and release of large quantities of toxins into the circulation ${ }^{2}$ and defined by a triad of muscle weakness, myalgia, and dark urine. ${ }^{3}$ electrolyte derangement occurs substantially in rhabdomyolysis including hypocalcemia in early stages, hypercalcemia, hyperkalemia and hyperphosphatemia. Other complications occur includes acute kidney injury, disseminated intravascular coagulation and compartment syndrome. ${ }^{4,5}$

Rhabdomyolysis associated with fenofibrate have been reported in patients with hypothyroidism, chronic renal failure, and co administration with statins. [1,6] Our patient's thyroid functions were normal, and he was not on statins previously. Creatinine values comes to normal following treatment excludes potential chronic kidney disease. Rhabdomyolysis in patient with no other potential risk factors have been rarely reported and never reported in Sri Lankan population.

Fluid resuscitation, identification and management of complications such as acute kidney injury, electrolyte derangement, compartment syndrome and disseminated intravascular coagulation are the mainstay of treatment and there is no specific treatment modalities identified yet. Overall mortality for rhabdomyolysis is around 5\%, though it is depend on associated comorbidity, and degree of muscle injury and acute kidney injury.

\section{Conclusion}

Rhabdomyolysis is a serious complication associated with fenofibrate therapy and early detection and appropriate treatments prevent morbidity and mortality. Patient should be alert on symptoms of rhabdomyolysis and advice to stop treatment and reach health care providerimmediately.

\section{Declaration of conflicting interests}

The authors declared no potential conflicts of interest with respect to the research, authorship and/or publication of this article.

\section{Informed consent}

Informed written consent was obtained from the patient for her anonymized information to be published in this article retrospectively.

\section{References}

1. Danis R, Akbulut A, Ozemen A, et al: Rhabdomyolysis-induced acute renal failure following fenofibratetherapy: a case report and literature review. Case Report Med 2010; 2010:16871689.

2. Beetham R. Biochemical investigation of suspected rhabdomyolysis. Ann Clin Biochem. 2000 Sep. 37 ( Pt 5):581-7

3. Cervellin G, Comelli I, Lippi G. Rhabdomyolysis: historical background, clinical, diagnostic and therapeutic features. Clin Chem Lab Med. 2010 Jun. 48(6):749-56.

4. Melli G, Chaudhry V, Cornblath DR. Rhabdomyolysis: an evaluation of 475 hospitalized patients. Medicine (Baltimore). 2005 Nov. 84(6):377-85.

5. Ward MM. Factors predictive of acute renal failure in rhabdomyolysis. Arch Intern Med. 1988 Jul. 148(7):1553-7.

6. Wu J, Song $\mathrm{Y}$, Li H, Chen J. Rhabdomyolysis associated with fibratetherapy: review of 76 published cases and a new case report. Eur J ClinPharmacol. 2009; 65:1169-1174. 